\title{
A FURTHER NOTE ON THE SENSORY CHARACTER OF BLACK.
}

\author{
BY JAMES WARD.
}

IN the first volume of this Journal ${ }^{1} \mathrm{I}$ raised anew the question, formerly often mooted, Is 'Black' a sensation? The evidence that it is seems nowadays so conclusive to the majority of psychologists and physiologists that anyone who advances reasons for thinking otherwise is classed among the circle-squarers, inventors of perpetual motions and other deluded cranks. No wonder then that for more than ten years my article was ignored. Yet now at last my old friend, Professor Titchener, has vouchsafed to give me the coup de grâce ${ }^{2}$.

But the Professor has been too merciful. After summarizing the psychological evidence, he remarks: "We should all, nevertheless, welcome an experimentum crucis." After all, then, the case is not yet quite a chose jugée. Nevertheless Professor Titchener thinks he can maintain (i) that no further psychological evidence is necessary, and (ii) that my 'review of visual theories' is really irrelevant to the main question.

(i) As to the summary of the psychological evidence which he regards as conclusive, I will venture at this stage on only two remarks.

(a) This summary, as it stands, reminds one of certain exciting trials in which the circumstantial evidence against the prisoner appears to be overwhelming, when lo! an alibi is forthcoming that alone suffices to dissipate it all. If black verily is a positive entity it may account for the facts marshalled to prove it; but there is one simple consideration that militates against this assumption, even if it does not completely

1 pp. 407-27.

2 "A Note on the Sensory Character of Black," Journal of Philosophy, Psychology, etc., March 2, 1916, pp. 113-21. 
overthrow it. Experience cannot begin with negation and vision cannot begin with black. This Hering fully admits: "the sensations of white and black," he says, "both alike are due to the influence of objective light, only with this difference that the white sensation [sic] is developed under the direct, but the black under the indirect, influence of the lightstimulus ${ }^{1} . "$

How Hering explains this indirect action of light I shall refer to later on. Meanwhile that he allows the sensation of black to presuppose that of light is enough for the present. The sensory character of black is allowed to be so far unique. This point is, in my opinion, essential to the case for the negative quality of black; and though it may not be sufficient alone, as I have already said, the case would be hopeless without it. Positive sensations, I have argued (p. 409), can occur in any order; not so negative. Among these, then, prima facie, at all events is the place of black. Professor Titchener, however, soon disposes of this crucial point to his own satisfaction, so that 'further argument,' he thinks, is needless. Unfortunately he has, $I$ fear, been misled by my final summary (p. 426), where blue and green--selected for quite other reasons-happen to be cited as being-unlike white and black-independent of the order of presentation. At any rate he supposes that I am 'speaking genetically' and so far 'speculatively.' He therefore thinks it pertinent to reply: "Blue, I take it, appeared earlier than green; and black and white appeared together" (p. 119). Genetically they did, no doubt: a fish that can see light does not have to wait for further differentiation of its light-sense before it can see black as it must do before it can see colours. All that is needed is the cessation of the objective light. My point, in short, is the obvious one that the experience of darkness presupposes the experience of light and 'answers to its absence. This and this only is the 'alibi' that bids fair to save black from all its troubles. So completely does Professor Titchener miss my point that he says: "Ward too assumes that the primitive sensation of sight consists of a "light' which ranges from complete darkness to dazzling brightness." What I actually said was "consists of the single quality we call 'light,' a quality which ranges in intensity from the zero of complete darkness, etc." (p. 408).

(b) "There is no ground for separating the blacks from the darks," Professor Titchener says in bringing his brief summary to a conclusion. It is this statement that leads me to my second remark. It would be strange that two terms should exist and have their equivalents in so

1 Zur Lehre vom Lichtsinn, S. A. 1874, p. 61. Italics mine. 


\section{A Further Note on Sensory Character of Black}

many languages, if all the world were, like Professor Titchener, unable "to distinguish between "complete darkness" and black.' The perception of such darkness implies 'an unlit space'-a dark-field, the perception of black on the other hand, is possible in a light-field. According to Hering, in fact, who also originally identified black and dark, the deepest black is possible only there, the darkness of an unlit space not being completely black ${ }^{1}$. Further, Hering now recognises various 'darks,' regarding blue and green as having each an Eigendunkeln, but, unlike Professor Titchener (p. 113), he recognises only one proper black - an ideal to which the nearest approach is made by contrast in the light-field ${ }^{2}$.

The language of everyday life agrees with this. For it there are various darks, always implying 'shade,' i.e. either diminished luminosity or diminished illumination; but there is only one true black, predicated not of colours but of things or forms as their colour. This black, like Hering's, is only perceptible in the light-field. This fact, viz. that there are occasions in which it is appropriate to speak of dark and others in which it is only appropriate to speak of black, is really the mainstay of Hering and his school. If then black never appeared in the lightfield their case would be desperate ${ }^{3}$. It is certain that we never perceive form without content, nor visible form without some colour. In this respect black is on a par with the rest. For all that it does not certainly follow but black itself is a positive sensation; though a 'body-colour,' i.e. a secondary quality in the epistemological sense, we must allow it to be. Blackness and darkness are then prima facie distinct. In the last resort possibly one may be resolved into the other; but it will make all the difference which. If 'black' can be resolved into 'dark' it will, I repeat, be difficult to prove that it is a colour. Even if 'dark' be resolved into an approximation to black, there is still much to do.

How on this supposition is the question to be settled? By direct appeal to psychological observation, Professor Titchener thinks. This, I believe, will go a long way towards establishing the privative character

1 Cf. Lichtsinn, p. 63.

${ }^{2}$ Cf. Lichtsinn, § 24 and "Grundzüge der Lehre vom Lichtsinn," Graefe-Saemisch Handbuch, II (1905), pp. $60 \mathrm{f}$. This change of view is due to his theory of "specific brightnesses.'

${ }^{8}$ I may be allowed here to repeat from my original article two quotations from v. Kries : $(a)$ "The unbiassed will always be inclined... [when the eyes are closed] to speak of a cessation of seeing, an absence of sensation (Nichtempfinden)." On the other hand, (b) "unbiassed introspection will never allow black to count as a lower degree of intensity of the sensation of white" (p. 411). 
of the darkness which befalls all colours alike; but does direct observation disprove the positive character of black? Black, we say, may answer to a portion of the light-field that is devoid of light. But we have to allow that at any rate form is just as readily perceived when it is black on a white ground as it is when white on a black one. Whereupon the attempt is made to turn the tables upon us. We have pressed the logical difference between privation and negation ${ }^{1}$ : the retort is to insist on that between negative and opposite. Black is not negative and therefore not privative: it is the opposite of white. Black and white are related much as land and water, island and lake. Very well, we rejoin, then they must be equally independent and black must have a positive stimulus and one as easily assigned as is that of white.

(ii) To this demand, however, as I have already mentioned, Professor Titchener demurs: it raises an issue that is, he holds, irrelevant to psychology. And he imagines that he has Hering's support in so restricting our question to the strictly psychological domain and abjuring all physiological incursions. But if physiologists who abjure psychology make statements that are psychologically barbarous or an affront to common sense, have we no right to intervene? As a matter of fact their avowed standpoint is psychophysical, or rather physicopsychical: psychology, as Professor Titchener, I believe, conceives it, they repudiate altogether ${ }^{2}$. But whether psychical facts are to be dubbed phenomenal or epiphenomenal our right to ask questions is surely indisputable. As to the particular question I have raised-its relevancy is admitted by everyone of the physiologists concerned. They begin by laying down psychophysical principles to which they appeal ${ }^{3}$. To every psychosis there is a causal or at least a corresponding neurosis, is the chief of these. We ask them for the neurosis answering to black. For all other visual sensations the physical stimulus is obvious-aetherial vibrations of some kind; but there is such direct stimulus for dark or black. If there is a stimulus at all it must be an internal state or change of some sort in the visual apparatus itself, retinal or central or both. So far all seem to be agreed, but as to the nature of this state or change there are two radically different views, that of Helmholtz - the resting state of the organ; and that of Hering

1 "Privation, so far as consciousness is concerned, is nothing else than absence," Professor Titchener maintains. The relevance to our question of the paragraph in which this dictum occurs I have failed to see and am uncertain therefore with what limitations, if any, this striking deliverance is to be understood.

2 Cf. Hering, Lichtsinn, p. 2.

3 Cf. Hering, Mach, v. Kries, G. E. Müller. 


\section{A Further Note on Sensory Character of Black}

-a restorative or assimilative process within it. The first will not account for a specific sensation, the second might, if it were not wholly problematic and inherently improbable.

It was against Helmholtz's view-that the resting state of the organ yields an actual sensation - that I urged the analogy between darkness and silence ${ }^{1}$. This Professor Titchener oddly enough takes to be argument on which I chiefly rely and he devotes to it much more space than I did: he even seems to have made a number of experiments to dispose of it. But I have reluctantly to confess that the drift of much of what he has said is beyond me; I will however try to deal with some of his points.

(1) In a note ( $p$. 410) I had spoken of 'a silence that could be heard,' and my critic is at pains to show that the proper expression would have been 'a silence that could be felt.' My remark obviously was not concerned with sensations at all, and therefore not with the various organic, kinaesthetic or other sensations that may under certain circumstances accompany the cessation of sound. What may be felt seems nothing to the point. All sorts of changes, sensory and emotional, all sorts of associations may accompany the cessation of light but nobody has argued that these help in the remotest degree to determine the sensory character of black. Similar concomitants seem as foreign to the like question in the case of silence. Macaulay ridiculed those who defended Charles I against the charge of being a bad king by proving that he was a good husband and a good father, a perfect gentleman, and so on. I should not like to say that my colleague at Cornell displays a similar ignoratio elenchi. I prefer to say that, with one exception ${ }^{2}$, I fail to see how his experiments and observations bear upon my point.

(2) My point was this: the cases in which we might refer to the cessation of sound as audible are-like "the silence in heaven for the space of half-an-hour'-cases of perception, where "consciousness, when

1 Urged long before by Fick, as Professor Titchener reminds me. I knew that well enough and $I$ have twice referred to Fick. To the article in Hermann's Handbuch $I$ should have referred too, had it been mentioned by Stumpf, with whose endeavour to disprove the analogy I was immediately concerned.

2 The observation that 'entotic phenomena' bar the way to 'the realisation of an auditory blank even in an objectively quiet place' (p. 115). To this there is the parallel of the entoptic phenomena (Helmholtz's Eigenlicht) in the case of objective darkness. The absolute ideal is unattainable either way. But at all events the blank in both cases is complete enough, as Fechner said (In Sachen der Psychophysik, p. 127), to put an end to the paradox that silence or blackness, if it were absolute, would; as such, yield us any positive sensation. 
there is nothing to hear, may still be auditory," as Professor Titchener himself has said (p. 116 fin.). But darkness and black in vision seem analogous to silence and pauses in sound, why then should the absence of positive sensation, generally conceded in the latter case, be disallowed in the former? This question, I feel, Professor Titchener has not directly faced. Although he admits ' my effort to distinguish between sensation and perception to be wholly justified' in itself (p. $120 n$.) he dismisses it here as 'only a Podsnappian flourish' (p. 115 fin.), because it ignores 'the various organic stimuli,' etc., that may be also in play. For lack of understanding, it may be, I am unable at present to concede this.

(3) Whereas sight is now preeminently the spatial sense, hearing is preeminently the temporal one, and as pauses therefore are for hearing (perceptually) auditory blanks so, I have contended, black may be regarded as, for sight, (perceptually) a visual blank. In illustration I referred to the parallel drawn by Preyer between the use of black in painting and the use of pauses in music, and again to the parallel drawn by Mach and v. Ehrenfals between 'time-shapes' and space-shapes (Gestaltqualitäten). As to the former, Professor Titchener complains that it is 'unhappily worded': I agree. However the analogy, I am disposed to think, still holds good'1. Chiaroscuro in painting answers to the crescendos and diminuendos of music and the limit of blackness in the one seems on a par with that of stillness in the other.

Anyhow the parallel between time-shapes and space-shapes is more instructive and Professor Titchener's çriticism less effective. He begins by pointing out that according to Mach "there is a peculiar, specific time-sensation." No doubt, 'according to Mach'; and there is a peculiar, specific space-sensation too, for that matter. But much as we owe to Mach, few, I imagine, would say that in elucidating the distinction between sensation and perception he has helped us at all. Yet Professor Titchener thinks otherwise; and accordingly he tries to refute me by further testimony from an authority to whom he supposes I had myself appealed. But no: shape qualities, temporal and spatial relations are not for me sensations but 'objects of a higher order,' as Meinong called them. It is useless, then, for Professor Titchener to turn upon me by saying that "the alternation of sound and silence is for Mach an alternation, not of sound

1 Against Professor Titchener's dictum that 'black is not indispensable to the painter's palette,' I may set Leonardo da Vinci's that it is. 


\section{A Further Note on Sensory Character of Black}

and nothing, but rather, of sound-time and of pure (sensory) time; the 'blank' interval has a specific time content." I never imagined that the blanks whether in sight or sound were absolutely nothing at all. They are perceived as forms and admit of measurement. An absolute blank for consciousness is clearly impossible: some specific time content there must be whenever we are aware of silence but that does not prevent silence itself being an auditory blank.

Against Hering, however, to urge the analogy between silence and darkness would be wasted labour till his arguments for the positive character of black, based on the facts of light-induction and contrast, had been met. My attempt to deal with these (pp. $413 \mathrm{f}$.), Professor Titchener has found 'very puzzling.' I do not think the fault is altogether his, and I must now try, while correcting some of his misapprehensions, to make my own meaning clearer.

Really the first point was to fix the meaning of contrast, but I left it till almost the last (p. 414 med.). "To call a difference of intensity "a contrast," says Professor Titchener, "simply begs the question." I prefer to say that it confounds two quite distinct things-a mere difference which may exist without comparison and a 'contrast' which cannot. When two intensities differ, it is possible to compare them, and if they differ greatly, to contrast them, as we constantly contrast extreme differences of degree of all sorts-e.g. great and small in respect of size, rich and poor in respect of wealth, weak and strong in respect of strength, \&c. But to assume that 'contrast' is given then and there, whenever two intensities are both positive and of opposite quality is, I maintain, equally to beg the question; or rather it is again to confound two entirely different things-opposition or antagonism-which can exist without comparison and 'contrast' which cannot. Yet that is the assumption which Hering makes. But contrast, as such, does not imply opposition. As the common use of the algebraic symbols + and - shews, opposition is disclosed by neutralisation or counteraction. It is to this fact that Hering appeals in ranging red and green, yellow and blue as Gegenfarben-a criterion which fails in the case of white and black. Contrast, I have said, is primarily a psychological concept, and strictly speaking-I will venture to add-its domain is always that of a linear scale of some sort. The zero point of this may be one of the extremes, as seems to be the case with black and white; or it may lie midway between them as in the case of red and green.

Deferring for the present the application of all this to the case of 
sound, I come now to the fact (or hypothesis) 1 of 'negative induction' as a physiological process accounting for the familiar darkening of the gray strip on a white ground. That there is no analogous process between a louder and a fainter sound I was well aware. But if darkness is negative, a 'negative' process which renders a given gray darker surely does not thereby tend to prove that darkness is positive. What was dark-the so-called Augenschwarz-being matched to a bodycolour appears, when contrasted with white, to be darker still. However produced the one psychological result is just this increased darkness.

"Leaving physiological differences aside," I then continued, "we can at least imagine a parallel in the case of sound, which would hold good psychologically at all events. Suppose we hear a loud sound of constant intensity and quality, and simultaneously a much fainter one of different quality $^{2}$. Let the intensity of the latter steadily diminish and the contrast in intensity between the two sounds will steadily increase; and there is a priori no reason why we should not attribute this growing contrast to the increasing stillness of the waning sound" (p. 413). But my critic sees no parallel: "the gray on the white ground does not grow continuously darker; on the contrary it gradually lightens." Quite true, and the objection is a perfectly natural one; and yet a little more care on my part might have obviated it. I regarded the faint sound as corresponding to the gray, certainly; but I conceived the intensity of this sound steadily waning, while the louder sound continued constant, to be the parallel situation, as regards contrast, to that of the constant gray in light-fields of increasing intensity. The objective variants and the constants, so to say, change places but there is a 'growing contrast' in both cases alike: in the increasing black owing to negative induction ${ }^{3}$, in the increasing stillness owing to the waning sound. The limit of such increasing stillness is an 'auditory blank' and the 'deepest black,' the limit of the visual series, Hering himself represents by zero (0). So much by way of clearing up Professor Titchener's misunderstandings. He repeats in this connexion his

1 There are difficulties in the way of Hering's position which I neglected to mention in my former paper. Cf. the masterly article by von Kries (Nagel's Handbuch, III, pp. 243-5).

i "The two sounds, heard together, if tones, would assuredly either blend or beat," Professor Titchener objects. Not necessarily, I believe, for perception; inasmuch as there are limits to the perceptibility of beats. Anyhow 'sounds' is the word used, not 'tones.'

${ }^{3}$ Hering himself gives figures illustrating this. Cf Grundzüge, p. 116. 


\section{A Further Note on Sensory Character of Black}

objection that an auditory blank has other 'sensory content' with which I have already tried to deal.

There is one criticism, it is the first that Professor Titchener makes, which I must admit to be-au pied de la lettre-effective. I had said that "in a light-field many colours may be distinguished, but in a dark field none." My critic reminds me that provided the light-field is light enough no colours can be distinguished in it; implying, of course, per contra that unless the dark-field is dark enough, colours can be distinguished in it. There is no denying this as ideally true. Practically we can only say with Hegel, that in the dark all cows are black. But theoretically it is just as true to say that in the light all cows are white. White then corresponds to one apex of our colour octahedron and black to the other. The interpretation of this superficial symmetry is however the important problem: it is in fact the very question now under discussion. If we regard the main axis of the colour manifold as symbolizing a simple intensive series ranging between a threshold value 0 and a lintel value 1 the disappearance of colours at the lower limit is a logical necessity. Their disappearance at the upper is just an empirical fact that might conceivably have been otherwise. Albeit it is an instance of a wider psychological generalisation, that "presentations of medium intensity are clearest ${ }^{1}$." Also the fact that the colour seen is a genetic differentiation of the light-sense helps to explain it.

The alternative is to regard black and white as, like red and green, equally positive and mutually antagonistic - the view, of course, of Hering which Professor Titchener defends. A blinding and dazzling black then becomes as truly a possibility as blinding and dazzling white is certainly a fact. "But whoever heard of a blinding black?" I asked, meaning of course a black so intense as to be painful like excessive light. Our eyelids are a protection against blinding white but what protection should we have against blinding black? Fortunately, as Hering assures us, there is really no such black ${ }^{2}$. Professor Titchener, however, has thought it pertinent to meet my question by quoting what Ebbinghaus has said- $\dot{a}$ propos of 'general adaptation'-about impenetrable blackness ${ }^{3}$. But my question referred not to adaptation but simply to sensation. To say that whereas a sensation of light may be blinding a sensation of black may be 'impenetrable' seems curiously awry. To me it seems to be as much off the lines as Professor Titchener's handling

1 Cf. Ebbinghaus, Arundzüge der Psychologie, 3rd ed. I. p. 752.

2 Lichtsinn, p. 89.

3 Op. cit. 1, p. 247. 
of silence as not an auditory blank because it has non-auditory accompaniments.

I have mentioned five 'difficulties' that Hering's theory entails (pp. 414-7) yet this is the only one with which my estimable colleague has attempted to deal. Considering the minuteness of his criticism of smaller points this is surprising and disappointing. His contention is that 'visual theories' are irrelevant and he prefers a short and easy method by way of psychological observation. Yet three of the remaining difficulties I have mentioned as besetting Hering's theory turn on points of psychology as do also many of my strictures on Wundt. His summary ruling-out of all this part of my discussion (p. 113) certainly does not suggest, and is not likely to beget, confidence in the strength of his case.

I made no rejoinder to Wundt's reply to my paper to which Professor Titchener refers. I must say that I did not think it very straightforward. When I complained of his habit of silently changing his opinions without admitting his previous mistakes he affected to believe that I twitted him for having the courage to live and learn. He felt exonerated from discussing my criticisms because they were essentially of an abstract and conceptual nature, and his one domain had always been experience! In a short final paragraph however he decides to ask me just one question. If black is not a sensation but the absence of a sensation why don't the totally blinded see black? What is more, he obligingly answers the question himself: Schwarzempfinden und Nichtempfinden sind zweierlei: in other words, the privative and the negative are not the same! So I had already said, though Professor Titchener does not agree.

(Manuscript received 3 May 1916.) 